Supporting Information for

\title{
Chemical boundary layer and its impact on air pollution in northern China
}

\author{
Xin Huang, ${ }^{1,2}$, , Jiantao Huang, ${ }^{1,2}$, Chuanhua Ren ${ }^{1,2}$, Jiaping Wang, ${ }^{1,2}$ Hongyue \\ Wang ${ }^{1,2}$, Jiandong Wang ${ }^{3}$, Hao Yu ${ }^{4}$, Jing Chen ${ }^{5}$, Jian Gao ${ }^{6}$, Aijun Ding ${ }^{1,2}$ \\ ${ }^{1}$ Joint International Research Laboratory of Atmospheric and Earth System Sciences, \\ School of Atmospheric Sciences, Nanjing University, Nanjing 210023, China \\ ${ }^{2}$ Jiangsu Provincial Collaborative Innovation Center for Climate Change, Nanjing 210023, \\ China. \\ ${ }^{3}$ Key Laboratory for Aerosol-Cloud-Precipitation of China Meteorological Administration, \\ School of Atmospheric Physics, Nanjing University of Information Science and \\ Technology, Nanjing 210044, China \\ ${ }^{4}$ Anhui Academy of Environmental Science Research, Hefei 230022, China \\ ${ }^{5}$ Shijiazhuang Meteorological Bureau, Shijiazhuang 050081, China \\ ${ }^{6}$ Chinese Research Academy of Environmental Sciences, Beijing 100012, China \\ Corresponding author: Xin Huang; Email: xinhuang@nju.edu.cn;
}

\section{Contents of this file}

Supplementary Methods

Figures S1 to S4

References 


\section{Supplementary Methods}

In-situ measurements of aerosol chemical composition

Concentrations of various aerosol components, including sulfate $\left(\mathrm{SO}_{4}{ }^{2-}\right)$, nitrate $\left(\mathrm{NO}_{3}^{-}\right)$, ammonium $\left(\mathrm{NH}_{4}^{+}\right)$, organic matters $(\mathrm{OM})$ and elemental carbon (EC), at Shijiazhuang were measured by MARGA (Monitor for AeRosols and Gases in ambient Air) and Sunset OC-EC instrumentation in 2017. For the data quality control of MARGA measurement, the instrument was calibrated on an hourly basis using internal standard liquid $(\mathrm{LiBr})$ to ensure a stable and reliable ion chromatograph. Data with $\mathrm{LiBr}$ response outside of $10 \%$ nominal concentrations were invalidated and excluded from further analysis. Similarly, values in the periods of malfunction, peak mis-integration and below the detection limit were also removed due to inaccuracies. Additionally, the ion balance of water-soluble ions was performed to filter the invalid values. The measurement data of water-soluble composition used in this study has good quality control, with a correlation $\mathrm{R}^{2}$ of 0.89 and a slope of 0.97 of the hourly-measured cation and anion aerosol species.

WRF-Chem simulation and PBL processes analysis

To get a clear picture of space- and time- varying pollution in PBL and quantitatively understand the respective contributions from chemical and physical processes, regional online-coupled meteorology-chemistry simulations are conducted based on WRF-Chem model (Weather Research and Forecasting model coupled with Chemistry, version 3.7.1). WRF-Chem model is a state-of-the-art model that includes a variety of coupled physical and chemical processes such as emission and deposition of pollutants, advection and diffusion, gaseous and aqueous chemical transformation, aerosol chemistry and dynamics, etc. ${ }^{1}$ The model has been widely used and evaluated against measurements, which has been further improved by optimizing parametrization of aqueous and heterogeneous chemistry in Asia., ${ }^{2} 3$ The model domain with a grid resolution of $20 \mathrm{~km}$ covered the eastern China and its surrounding areas to get synoptic forcing. There are 35 vertical layers from the ground level to the top pressure of $50 \mathrm{hPa}$, in which more than 10 layers are settled under 1000 meters to better describe boundary layer processes. The simulation is conducted from November 2017 to February 2018. The initial and boundary meteorological conditions were the NCEP global final analysis (FNL) data. NCEP Automated Data Processing (ADP) surface and global upper air observational weather data of wind, temperature and moisture are assimilated to better characterize the regional transport pattern of air pollution. The Yonsei University planet boundary layer (YSU) scheme is applied to parameterize the boundary layer processes in this simulation. Other key parameterization options are the Noah land surface scheme to describe the landatmosphere interactions, the Lin microphysics scheme with the Grell cumulus parameterization to reproduce the cloud and precipitation processes, and the RRTMG short- and long-wave radiation scheme. For the numerical representation of atmospheric chemistry, Carbon-Bond photochemical mechanism combined with MOSAIC (Model for Simulating Aerosol Interactions and Chemistry) aerosol module. Both natural and anthropogenic emissions were included for the regional WRF-Chem modeling in the present work. MEGAN (Model of Emissions of Gases and Aerosols from Nature) module embedded in WRF-Chem model is used to calculate biogenic emissions online. It estimates the net emission rates of isoprene, monoterpene and other biogenic VOCs from terrestrial 
ecosystems into the above-canopy atmosphere. Soil-derived dust emission is characterized by GOCART emission schemes. Anthropogenic emissions from power plants, residential combustion, industrial processes, on-road mobile sources and agricultural activities were derived from the MEIC, which is described above. Emissions outside China was obtained from the MIX Asian emission inventory. ${ }^{4}$

To investigate the contributions of each individual physical and chemical process to variations of secondary pollutants like $\mathrm{O}_{3}, \mathrm{SO}_{4}{ }^{2-}, \mathrm{NO}_{3}{ }^{-}$, we performed diagnostic analysis in WRF-Chem modeling. The change rate of chemical species concentrations due to the dynamic and chemical production/loss processes are described by a set of mass continuity equations. In this work, we recorded changes in concentrations due to vertical mixing due to PBL processes (vmix), gas-phase and cloud-phase chemistry (chem) at each integration step. The detailed description of the diagnosis and implications can be found in the previous publications. ${ }^{5}$ 


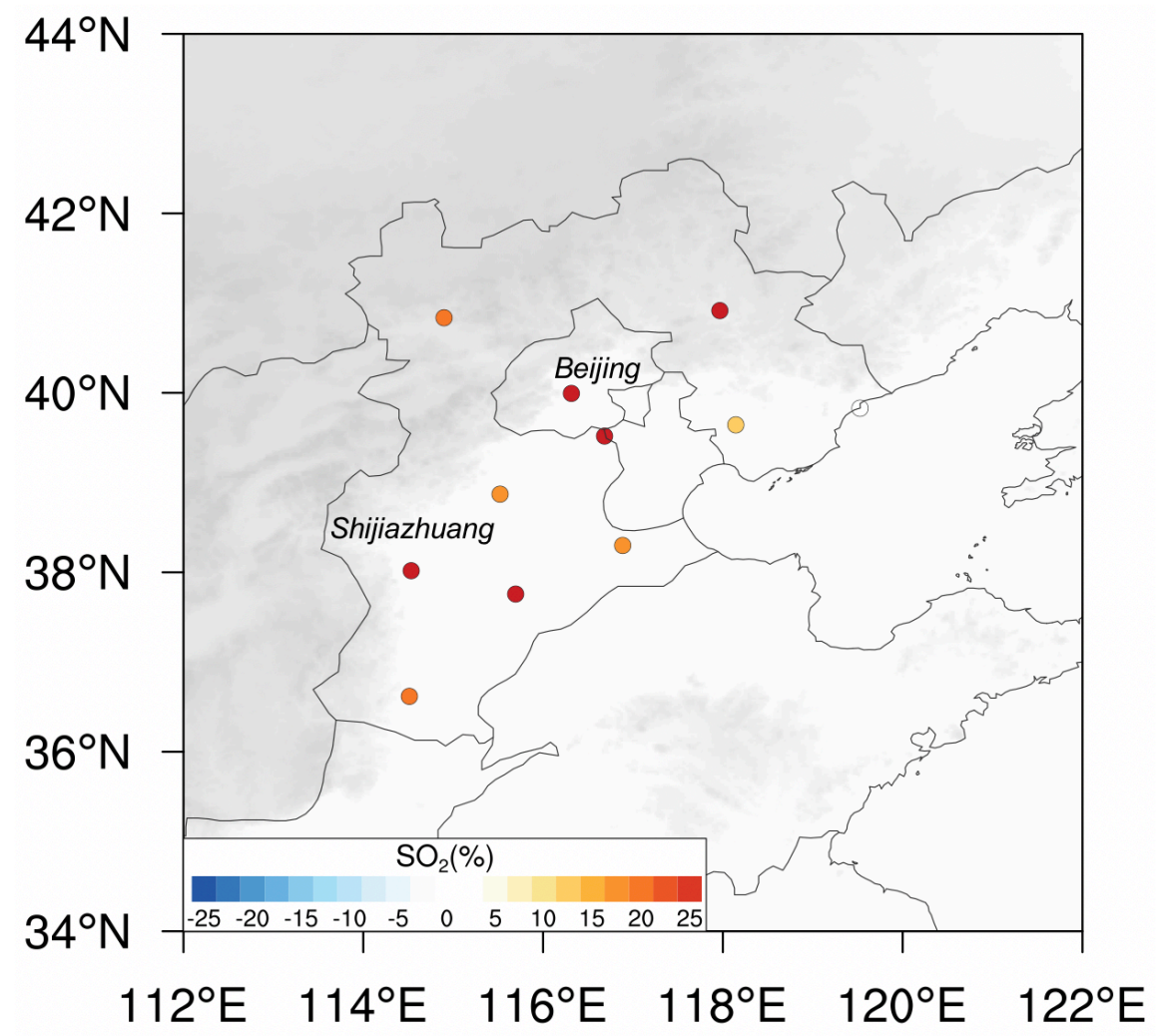

Figure S1. Obvious morning $\mathrm{SO}_{2}$ increase when PBL starts to rise. Averaged wintertime $\mathrm{SO}_{2}$ increase from 6:00LT to 9:00LT in Beijing-Tianjin-Hebei region based on the in-situ measurements from 2016-2019. 

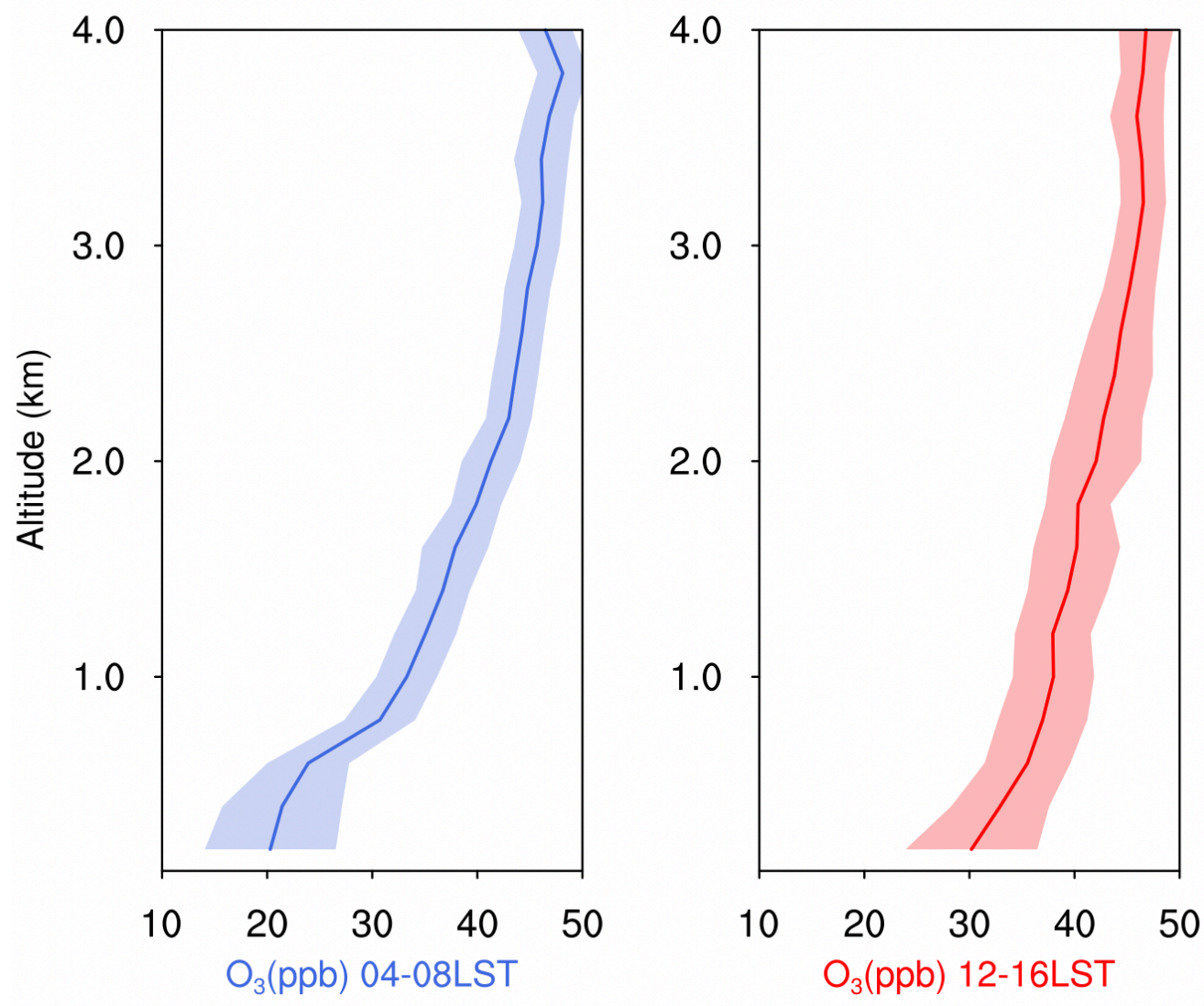

Figure S2. Long-term aircraft observations on vertical profiles of ozone concentration in early morning and afternoon in Beijing. Statistics of aircraft measurements on wintertime ozone concentration profiles in Beijing during 1997-2017. The total number of available aircraft profile measurement is 203 in winter. The solid lines present the average and the shaded areas show the $25-75^{\text {th }}$ percentile. 

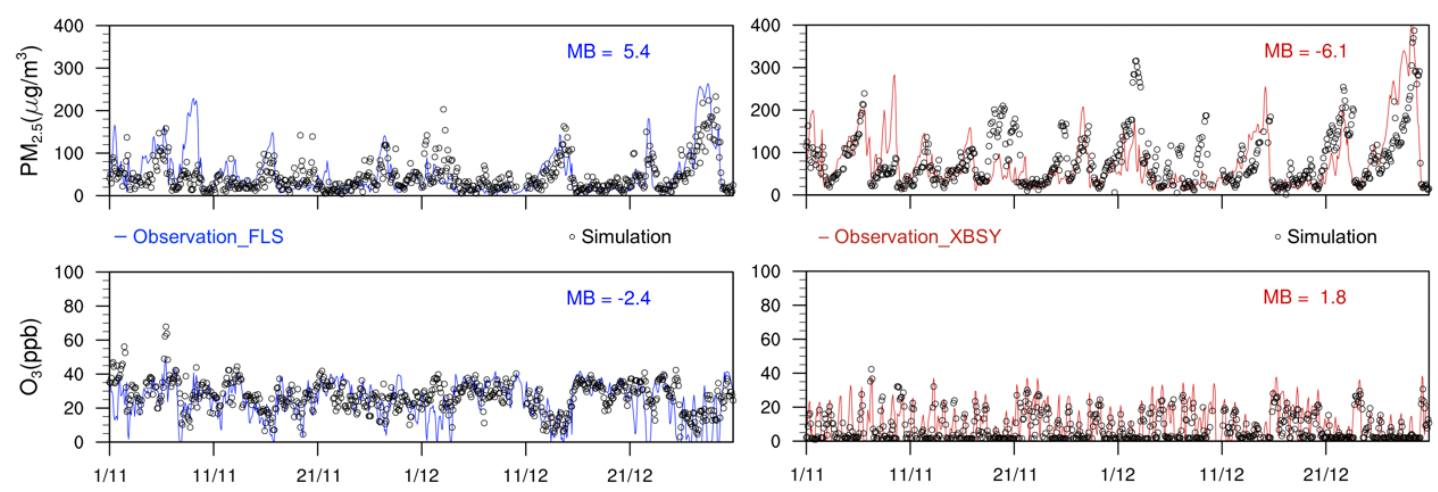

Figure S3. Evaluation of WRF-Chem model performance on capturing hourly variations of $\mathrm{PM}_{2.5}$ and $\mathrm{O}_{3}$ concentrations in Beijing-Tianjin-Hebei region. Comparisons of hourly observed and modeled $\mathrm{PM}_{2.5}$ and $\mathrm{O}_{3}$ concentrations at FLS and XBSY stations in the winter of 2017. Note that solid lines and circles show the simulation and observations, respectively. Mean bias (MB) of model simulation are marked in the top right corners. 


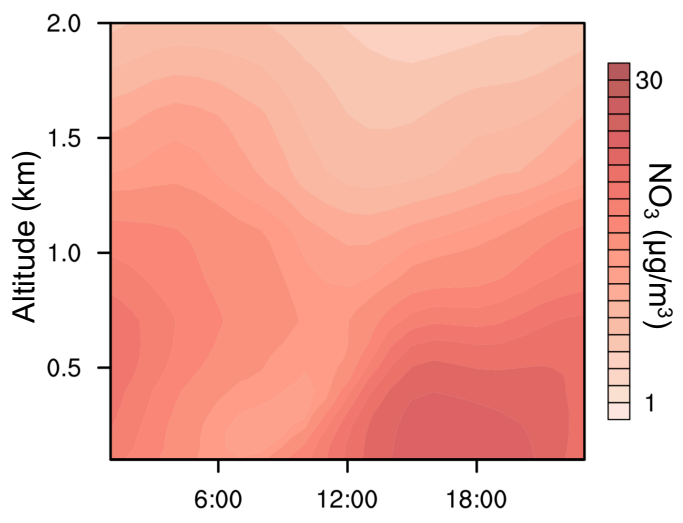

Figure S4. Vertical structure of nitrate aerosol. Modeled diurnal variation and vertical distributions of nitrate aerosol concentration at Shijiazhuang for the winter of 2017. 


\section{References}

1. Grell, G. A.; Peckham, S. E.; Schmitz, R.; McKeen, S. A.; Frost, G.; Skamarock, W. C.; Eder, B., Fully coupled "online" chemistry within the WRF model. Atmos Environ 2005, 39, (37), 6957-6975.

2. Huang, X.; Song, Y.; Zhao, C.; Li, M. M.; Zhu, T.; Zhang, Q.; Zhang, X. Y., Pathways of sulfate enhancement by natural and anthropogenic mineral aerosols in China. $J$ Geophys Res-Atmos 2014, 119, (24), 14165-14179.

3. Huang, X.; Song, Y.; Zhao, C.; Cai, X. H.; Zhang, H. S.; Zhu, T., Direct Radiative Effect by Multicomponent Aerosol over China. J Climate 2015, 28, (9), 3472-3495.

4. Li, M.; Zhang, Q.; Kurokawa, J.; Woo, J. H.; He, K. B.; Lu, Z. F.; Ohara, T.; Song, Y.; Streets, D. G.; Carmichael, G. R.; Cheng, Y. F.; Hong, C. P.; Huo, H.; Jiang, X. J.; Kang, S. C.; Liu, F.; Su, H.; Zheng, B., MIX: a mosaic Asian anthropogenic emission inventory under the international collaboration framework of the MICS-Asia and HTAP. Atmos Chem Phys 2017, 17, (2), 935-963.

5. $\quad$ Wang, T. Y.; Huang, X.; Wang, Z. L.; Liu, Y. L.; Zhou, D. R.; Ding, K.; Wang, H. Y.; Qi, X. M.; Ding, A. J., Secondary aerosol formation and its linkage with synoptic conditions during winter haze pollution over eastern China. Sci Total Environ 2020, 730. 